06.5

\title{
Исследование механизма наноструктурирования приповерхностных слоев титана при воздействии лазерными импульсами наносекундной длительности
}

\author{
(С) А.Ю. Токмачева-Колобова \\ Институт проблем химической физики РАН, Черноголовка, Московская обл., Россия \\ Национальный исследовательский технологический университет „МИСиС“, Москва, Россия \\ Физико-технический институт им. А.Ф. Иоффре РАН, Санкт-Петербург, Россия \\ E-mail: anastasiia.misis@gmail.com
}

Поступило в Редакцию 30 июля 2020 г.

В окончательной редакции 28 октября 2020 г.

Принято к публикации 28 октября 2020 г.

\begin{abstract}
Исследована микроструктура приповерхностных слоев субмикрокристаллического технического титана марки ВТ1-0 после лазерной обработки под слоем воды импульсами наносекундной длительности с плотностью мощности облучения $F=2 \mathrm{GW} / \mathrm{cm}^{2}$. Обнаружен эффект значительного измельчения исходной субмикрокристаллической структуры до наноструктурированного состояния в тонком приповерхностном слое толщиной порядка $1 \mu \mathrm{m}$. Рассматривается возможность реализации физических механизмов наноструктурирования приповерхностных слоев, связанных с фазовой перекристаллизацией или ротационной динамической рекристаллизацией.
\end{abstract}

Ключевые слова: титан, импульсная лазерная обработка, микроструктура, наноструктурирование.

DOI: 10.21883/PJTF.2021.03.50575.18492

Известно, что при фокусировке импульса короткой (наносекундной) или ультракороткой (фемтосекундной/пикосекундной) длительности с плотностью мощности лазерного излучения $F>10^{9} \mathrm{~W} / \mathrm{cm}^{2}$ на поверхность материала происходит испарение и унос приповерхностных слоев (абляция) с образованием плазмы (с высокими температурой и давлением), которая при расширении формирует ударные волны. Использование ограничивающего слоя, в частности воды, позволяет усилить давление, генерируемое в ударной волне, в 4-10 раз и приводит к увеличению длительности ее воздействия в 2 раза по сравнению с аналогичными величинами в режиме облучения, называемом прямой абляцией [1]. На данном принципе основан метод лазерной ударноволновой обработки (лазерной ковки, англ. laser shock peening). В зависимости от длительности импульса и величины энергии в импульсе, а также от диаметра пучка и других параметров такой обработки изменение микроструктуры приповерхностного слоя можно наблюдать до различной глубины.

Так, в работе [2] после обработки крупнозернистого титанового сплава ТС17 (системы $\mathrm{Ti}-\mathrm{Al}-\mathrm{Mo}-\mathrm{Cr}-\mathrm{Sn}-\mathrm{Zr}-\mathrm{Fe}$ ) под миллиметровым слоем воды лазерными импульсами длительностью $15 \mathrm{~ns}$ с плотностью мощности излучения $F=9.5 \mathrm{GW} / \mathrm{cm}^{2}$ в приповерхностном слое материала толщиной до $200 \mu \mathrm{m}$ наблюдалось значительное измельчение исходных зерен $(43 \mu \mathrm{m})$ до субмикронного размера $(\sim 400 \mathrm{~nm})$ в приповерхностном слое толщиной $30 \mu \mathrm{m}$. В [3] после обработки мощными наносекундными лазерными импульсами (15 J в импульсе) сплава $\mathrm{Ti}-6 \mathrm{Al}-4 \mathrm{~V}$ под тонким слоем воды $\left(F=5 \mathrm{GW} / \mathrm{cm}^{2}\right)$ обнаружено, что толщина упрочненного слоя (при измерениях на поперечном срезе) достигает одного миллиметра.

В настоящее время в литературе имеется большое число работ по исследованию влияния лазерной ударноволновой обработки на структуру и свойства приповерхностных слоев металлов и сплавов, в том числе сплавов на основе титана. Однако ранее такие сплавы изучались после штатной термомеханической обработки или в исходном рекристаллизованном состоянии. Представляет интерес исследование возможности и механизма дальнейшего измельчения исходной субмикрокристаллической (СМК) структуры металлических материалов путем наносекундного лазерного облучения под слоем воды, актуальность этого была обоснована ранее в работе [4].

В качестве материала для исследований выбран технический титан марки ВТ1-0, химический состав которого приведен в работе [5]. СМК-состояние в рассматриваемом материале было сформировано методами механико-термической обработки по схеме, описанной в [5]. Лазерная обработка проводилась на установке „Минимаркер-2“ со следующими параметрами облучения: длина волны $\lambda=1064 \mathrm{~nm}$, длительность импульса $\tau \sim 100 \mathrm{~ns}$, энергия в импульсе $E \approx 2 \mathrm{~mJ}$, частота следования импульсов $v=50 \mathrm{kHz}$, скорость сканирования $v=1500 \mathrm{~mm} / \mathrm{s}$, плотность мощности энергии излучения $F=2 \mathrm{GW} / \mathrm{cm}^{2}$. Обрабатываемые образцы находились под слоем воды толщиной $2 \mathrm{~mm}$ (выбор толщины водного слоя проведен на основе данных работы [6]). Тонкие фольги (ламеллы) из приповерхностного слоя образ- 

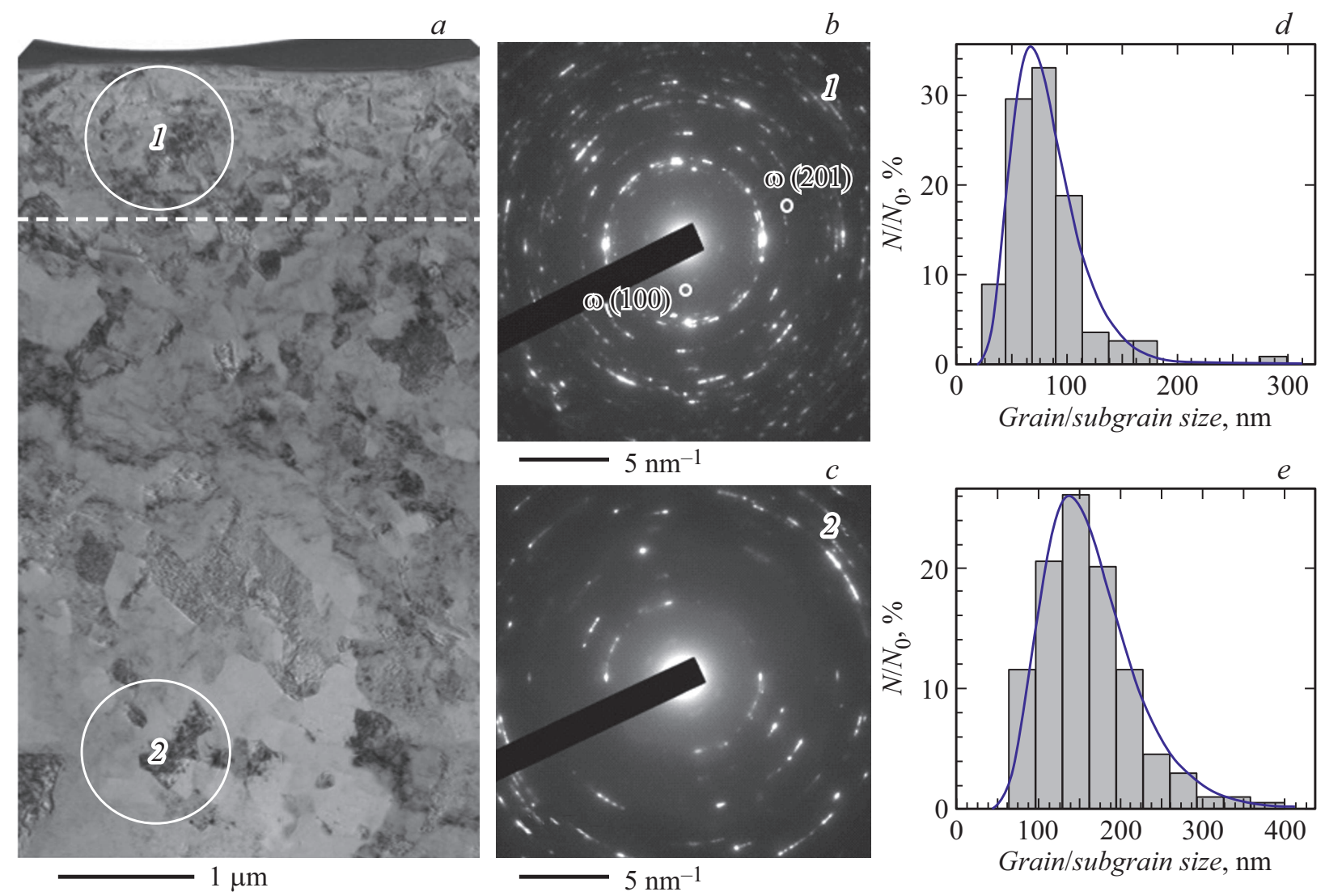

$a-$ светлопольное изображение микроструктуры технического титана ВТ1-0 после лазерной обработки импульсами наносекундной длительности под водой. Штриховая линия показывает условные границы непосредственно примыкающего к поверхности наноструктурированного тонкого приповерхностного слоя. $b$ и $c$ - электронограммы, полученные соответственно для областей 1 и 2 , отмеченных на части $a$. Кружками на части $b$ выделены располагающиеся по окружностям рефлексы от частиц $\omega$-фазы. $d$ и $e-$ гистограммы распределения элементов зеренно-субзеренной структуры по размерам в приповерхностном слое и на удалении от него соответственно.

цов были получены известным методом „сross-section“ с использованием сфокусированных ионных пучков в колонне растрового электронно-ионного микроскопа FEI Scios Dual Beam. Исследование микроструктуры и фазового состава полученных фольг проводилось на просвечивающем электронном микроскопе JEOL JEM-2100 в режимах светлого и темного поля, а также микродифракции. С использованием программного обеспечения ImageScope определялся средний размер элементов зеренно-субзеренной структуры в соответствии с известными методиками.

В исходном состоянии исследуемый материал имеет зеренно-субзеренную структуру со средним размером элементов структуры $\sim 150 \mathrm{~nm}$, обозначаемую в литературе как СМК- или ультрамелкозернистая структура [7]. Как можно видеть из рисунка, $a$, в структуре титана после рассматриваемой лазерной обработки отчетливо выделяется тонкий (толщиной порядка $1 \mu \mathrm{m}$ ) подповерхностный слой со значительно измельченной исходной СМК-структурой до наноструктурированного состояния, представляющего собой зеренно-субзеренную смесь с размером элементов структуры $\sim 75 \pm 6 \mathrm{~nm}$ (см. ри- сунок, $d)$. Квазикольцевая электронограмма, полученная для данной области, имеет высокую плотность расположения точечных рефлексов по окружностям (см. рисунок, $b$ ), что свидетельствует о широком спектре углов разориентировки между элементами и высокой дисперсности структуры. Кроме того, на электронограмме присутствуют две слабые по интенсивности окружности, соответствующие отражениям от кристаллографических плоскостей (100) и (201) $\omega$-фазы (фазы высокого давления в титане). Это является прямым подтверждением формирования ударной волны в рассматриваемом случае, как было обнаружено ранее с участием автора для исследуемого сплава при других условиях лазерной обработки [8].

На удалении от поверхности более чем на $1 \mu \mathrm{m}$ сохраняется исходная СМК-структура. Средний размер элементов зеренно-субзеренной структуры составляет $\sim 160 \pm 10 \mathrm{~nm}$ (части $a$ и $e$ рисунка). Электронограмма (см. рисунок, $c$ ), полученная для указанной области, имеет также квазикольцевой характер, но со значительно меньшей плотностью рефлексов, чем отмечалось выше для тонкого приповерхностного слоя. Вместе с 
тем для электронограмм как в исходном состоянии [7], так и после лазерной обработки характерно дуговое размытие рефлексов, связанное, как известно, с высокой плотностью дефектов кристаллического строения и остаточными внутренними напряжениями.

В обзоре [9] отмечалось, что наноструктурирование в сплавах с полиморфным фазовым превращением при высокоскоростной деформации, в том числе при воздействии импульсного лазерного пучка, может быть результатом фазовой перекристаллизации. Согласно данным $[10], \alpha$-фаза титана переходит в $\omega$-фазу в интервале давлений от 2 до $12 \mathrm{GPa}$ в зависимости от условий нагружения. Оценка по известной формуле Фаббро [1] величины пикового давления, создаваемого ударной волной в исследуемых в настоящей работе условиях, дает $P=1.9 \mathrm{GPa}$, что соответствует возможности появления $\omega$-фазы. В работе [10] сделано предположение, что при превращении $\alpha \rightarrow \omega$ в чистом титане остаются равномерно распределенные по объему ультрадисперсные остаточные включения $\alpha$-фазы, которые будут зародышами для дальнейшего роста $\alpha$-фазы в процессе обратного превращения $\omega \rightarrow \alpha$ при снятии нагрузки. Таким образом может быть реализован процесс формирования наноструктурированного состояния. Возможно, данный механизм наноструктурирования при фазовом превращении реализуется и в исследованных в настоящей работе условиях.

Другим возможным механизмом наноструктурирования в исследуемом случае является ротационная динамическая рекристаллизация в процессе высокоскоростной деформации, вызванной лазерной ударно-волновой обработкой, как это было обнаружено в [2]. При этом высокоскоростное деформирование может быть рассмотрено как квазиадиабатический процесс, при котором разогрев материала обусловлен переходом энергии, связанной с работой пластической деформации, в тепло, а охлаждению способствует слой воды на поверхности облучаемых лазером образцов. По аналогии с анализом, проведенным в работе [2], оценим продолжительность процесса ротационной динамической рекристаллизации, связанного с переходом малоугловых границ в большеугловые при увеличении угла разориентировки за счет накопления в них дислокаций одного знака. Оценим время, необходимое для увеличения угла разориентировки субграниц от $3^{\circ}$ (значение моды для распределения разориентировок на субграницах в исходной СМК-структуре по данным [7]) до $15^{\circ}$ и тем самым их трансформации в большеугловые границы, по формуле:

$$
t=\frac{L k T f(\theta)}{4 \delta D_{b 0} \eta \exp \left(-Q_{b} / R T\right)},
$$

где $L$ - диаметр исходных субзерен (предполагается, что их размер существенно не изменяется, а происходит преимущественно увеличение взаимной разориентировки) $[\mathrm{m}], k-$ постоянная Больцмана $[\mathrm{J} / \mathrm{K}], T-$ температура $[\mathrm{K}], \delta$ - толщина границы зерна $[\mathrm{m}]$,
$D_{b 0}$ - предэкспоненциальный множитель при расчете коэффициента зернограничной диффузии $\left[\mathrm{m}^{2} / \mathrm{s}\right], \eta-$ энергия границ зерен $\left[\mathrm{J} / \mathrm{m}^{2}\right], Q_{b}-$ энергия активации зернограничной диффузии $[\mathrm{kJ} / \mathrm{mol}], \theta-$ угол разориентировки $\left[^{\circ}\right] ; f(\theta)$ вычисляется по формуле, приведенной в [2].

Возьмем для расчета $L=75 \mathrm{~nm}, k=1.38 \cdot 10^{-23} \mathrm{~J} / \mathrm{K}$, $\eta=1.19 \mathrm{~J} / \mathrm{m}^{2} \quad[2], \quad \delta D_{b 0}=1.1 \cdot 10^{-16} \mathrm{~m}^{3} / \mathrm{s} \quad[11]$, $Q_{b}=82 \mathrm{~kJ} / \mathrm{mol} \quad[11], \quad f\left(\theta=15^{\circ}\right)=0.38, \quad$ температуру адиабатического разогрева в исследуемых условиях $T=1702 \mathrm{~K}$ и получим $t \approx 0.4 \mathrm{~ns}$. Для увеличения угла разориентировки границ до $20^{\circ}$ потребуется промежуток времени порядка $1 \mathrm{~ns}$. При этом длительность ударноволнового воздействия составляет $\sim 200 \mathrm{~ns}$, поскольку облучение происходит под водой [1]. Следовательно, проведенная оценка подтверждает принципиальную возможность наноструктурирования исследуемого материала по механизму ротационной динамической рекристаллизации в исследуемых условиях.

Таким образом, обнаруженный в работе на примере технического титана ВТ1-0 эффект дальнейшего значительного измельчения исходной субмикрокристаллической структуры до наноструктурированного состояния (на глубину до $1 \mu \mathrm{m}$ ) в условиях ударно-волновой импульсной лазерной обработки импульсами наносекундной длительности под слоем воды (лазерная ковка) может быть связан с фазовой перекристаллизацией или протеканием процесса ротационной динамической рекристаллизации.

\section{Благодарности}

Автор выражает благодарность за помощь в проведении лазерной обработки сотрудницам Международной научной лаборатории лазерных микро- и нанотехнологий и систем Университета ИТМО (Санкт-Петербург) Г.В. Одинцовой и Ю.Ю. Карлагиной.

\section{Финансирование работы}

Исследование в основной части, связанной с изучением структурно-фазового состояния технического титана, выполнено за счет гранта Российского научного фонда № 19-12-00221, а в части подготовки тонких фольг (ламелл) из заданных локальных участков образца за счет гранта Российского фонда фундаментальных исследований № 19-32-90017 на оборудовании центров коллективного пользования ФНИЦ „Кристаллография и фотоника“ РАН и Национального исследовательского технологического университета „МИСиС“.

\section{Конфликт интересов}

Автор заявляет, что у нее нет конфликта интересов. 


\section{Список литературы}

[1] R. Fabbro, J. Fournier, P. Ballard, D. Devaux, J. Virmont, J. Appl. Phys., 68 (2), 775 (1990). DOI: 10.1063/1.346783

[2] Y. Yang, H. Zhang, H. Qiao, J. Alloys Compd., 722, 509 (2017). DOI: 10.1016/j.jallcom.2017.06.127

[3] X.C. Zhang, Y.K. Zhang, J.Z. Lu, F.Z. Xuan, Z.D. Wang, S.T. Tu, Mater. Sci. Eng. A, 527 (15), 3411 (2010). DOI: $10.1016 / \mathrm{j} . \mathrm{msea} .2010 .01 .076$

[4] С.С. Манохин, А.Ю. Токмачева-Колобова, Ю.Ю. Карлагина, В.И. Бетехтин, А.Г. Кадомцев, М.В. Нарыкова, Ю.Р. Колобов, Поверхность. Рентгеновские, синхротронные и нейтронные исследования, № 1, 67 (2021). DOI: $10.31857 / \mathrm{S} 1028096020120195$

[5] М.Б. Иванов, Ю.Р. Колобов, Е.В. Голосов, И.Н. Кузьменко, В.П. Вейнов, Д.А. Нечаенко, Е.С. Кунгурцев, Рос. нанотехнологии, 6 (5-6), 108 (2011). [Пер. версия: 10.1134/S1995078011030074].

[6] T. Takata, M. Enoki, P. Chivavibul, A. Matsui, Yu. Kobayashi, Mater. Trans., 57 (10), 1776 (2016). DOI: $10.2320 /$ matertrans.M2016150

[7] Ю.П. Шаркеев, А.Д. Братчиков, Ю.Р. Колобов, А.Ю. Ерошенко, Е.В. Легостаева, Физ. мезомеханика, 7 (S1-2), 107 (2004).

[8] Yu.R. Kolobov, A.Yu. Tokmacheva-Kolobova, S.S. Manokhin, S.A. Bozhko, G.V. Khramov, in Proc. of the eighteenth Israeli-Russian Bi-National Workshop (Ariel University Press, Ariel, 2019), p. 95-104.

[9] Ю.Р. Колобов, Изв. вузов. Физика, 61 (4), 11 (2018). [Пер. версия: 10.1007/s11182-018-1440-4].

[10] I.V. Nelasov, A.G. Lipnitskii, A.I. Kartamyshev, V.N. Maksimenko, Yu.R. Kolobov, AIP Conf. Proc., 2053 (1), 030047 (2018). DOI: 10.1063/1.5084408

[11] А.Г. Липницкий, И.В. Неласов, Ю.Р. Колобов, Физ. мезомеханика, 16 (1), 67 (2013). 